\title{
Artículos
}

\section{Irak y la reconstrucción de Estados Unidos}

\author{
Francisco Javier Ibisate S. J.
}

\section{Resumen}

En este artículo, el autor hace un análisis sobre la actuación de Estados Unidos antes, durante y después del ataque que hiciera esta nación contra Irak. Explica las nuevas alianzas que se hilaron y deshilaron entre las naciones, los "pactos contra el terrorismo", la Resolución 1441, emitida por el Consejo de Seguridad de Naciones Unidas, etc., y la resolución presentada por los gobiernos de Estados Unidos, Inglaterra y España, declarando que como Irak no había aprovechado la última posibilidad ofrecida con la resolución 1441, quedaba legitimada la "guerra preventiva". Declaración que estaba en franca oposición al llamado "pacto franco-alemán", que buscaba alternativas pacíficas con miras a evitar la guerra en Irak. Es obvio que se ha agredido y debilitado el papel conciliador de Naciones Unidas, una de las pocas instituciones mundiales capaces de "construir la confianza" para respetar los derechos humanos durante las guerras y para buscar la equidad económica. Asimismo, también ha quedado debilitada "la unidad de la Unión Europea". Ahora, de cara a la futura paz del mundo, nos preguntamos: ¿Quién y cómo se llevará a cabo la reconstrucción de Irak? ¿El Pentágono, el Departamento de Estado, Naciones Unidas con la comunidad internacional? ¿La reconstrucción de la economía estadounidense se hará gracias a la destrucción de la economía iraquí? y ¿quién y cuándo podrá reconstruir al "Dios, la conciencia y la historia" del actual gobierno de Estados Unidos?

I. Catedrático del departamento de Economía de la UCA.

$$
\text { R72964 }
$$




\section{EI largo camino de Bagdad}

Alea iacta est: "la decisión está tomada". En sus discursos del 6 y 16 de marzo, el presidente G. W. Bush manifestó, ante el pueblo norteamericano, que la decisión bélica, la guerra preventiva, era legítima y justificada: "Estoy convencido de que el pueblo norteamericano comprende que, cuando se trata de nuestra seguridad, si debemos actuar vamos a actuar y no necesitamos realmente la aprobación de Naciones Unidas para hacerlo. No necesitamos el permiso de nadie" (Le Monde, 8 de marzo de 2003). "El mundo está ante unos días cruciales; mañana será el momento de la verdad. El régimen iraquí tiene que desarmarse o será desarmado por la fuerza... El Consejo de Seguridad de Naciones Unidas incumplió sus responsabilidades $y$, por lo tanto, nosotros vamos a tomar las nuestras... Que Dios bendiga a Norte América" (Ibíd.).

Luego del 17 de marzo se han renovado las multitudinarias manifestaciones, No War, en las principales ciudades y capitales del mundo entero. Una de las primeras voces que ha condenado la guerra fue la del Papa Juan Pablo II: "Quien decida que todos los medios pacíficos de los que dispone el derecho internacional se han agotado, tendrá que asumir una grave responsabilidad ante Dios, ante su propia conciencia y ante la historia". Ahora buscamos en Internet cómo se llevará a cabo la reconstrucción de Irak: ¿el Pentágono, el Departamento de Estado, Naciones Unidas con la comunidad intemacional? Estos son los interrogantes, en la primera quincena de marzo, porque aparecen grietas y tensiones entre ambas orillas del Atlántico y muchos se preguntan si Naciones Unidas ha fracasado.

De cara a la futura paz del mundo, sin embargo, se alza otra pregunta: ¿cuándo y quién reconstruirá a Estados Unidos, a su gobierno actual, ante Dios, ante su conciencia y ante la historia? Porque Bush dijo que él oraba todos los días por la paz. Y si estallara la guerra, rogaría por la seguridad de las tropas norteamericanas y por la seguridad de los iraquíes inocentes. "Mi fe me sostiene porque rezo cada día. Pido que ella me guíe y me dé sabiduría y fuerza. Rezo por la paz. Rezo por la paz" (Ibíd.). La guerra contra Irak adquiere el tono de una "cruzada".

La paz del mundo seguirá siendo inestable, si cohabitan "dos conciencias, dos dioses, dos historias y dos Naciones Unidas". Todavía recordamos las palabras del presidente Bill Clinton, en la cum- bre del milenio de Naciones Unidas, en Nueva York, en septiembre del año 2000: "Aquellos que en mi país, o en cualquier otra parte, creen que podemos prescindir de Naciones Unidas o imponer nuestra voluntad sobre ella, malinterpretan la historia y no comprenden el futuro. Nos guste a no, somos cada vez mas interdependientes. Debemos buscar soluciones en las cuales todas las partes implicadas puedan sentirse parcialmente victoriosas y alejarnos de aquellas opciones en que se exige la total derrota de alguien". Este discurso se interpretó como el "testamento político" de Clinton (ECA, 2000, p. 907). Recordamos las palabras que M. Gorbachov dijera hace poco más de un año: "Las víctimas de los atentados del 11 de septiembre en Estados Unidos no habrian muerto en vano, si el mundo aprovechara la ocasión para mirarse en el espejo y establecer un compromiso moral, sin caer en el pánico". Ahora tenemos que decir que ha primado el pánico y el instinto de venganza sobre el compromiso moral. ¿Quién podrá reconstruir moralmente al gobierno de Estados Unidos? ¿La historia?

\section{El "eje del mal"}

En vísperas de iniciarse el Foro Económico Mundial de Davos, en Nueva York, y el Foro Social Mundial, en Porto Alegre, en febrero de 2002, Bush hizo pública la gran amenaza del mundo, el eje del mal, la estructuración mundial del terrorismo: "El mundo civilizado está amenazado por peligros nunca vistos... La guerra contra el terrorismo no ha hecho más que comenzar. Países concretos presentan un grave peligro. Corea del Norte es un régimen que se está armando con misiles y armas de destrucción masiva. Irán está decidida a adquirir estas armas y a exportar el terrorismo. Irak sigue demostrando su hostilidad hacia Norteamérica y alimenta el terrorismo. El régimen iraquí trata desde hace diez años de desarrollar el bacilo de carbón, el gas de combate y las armas nucleares... Miles de peligrosos asesinos, entrenados para matar de muchas maneras, sostenidos por regímenes 'fuera de ley' están diseminados por el mundo como bombas de efecto retardado, dispuestas a explotar de repente"... (Le Monde, 30 de enero de 2002).

Dentro y fuera del Foro de Davos, este discurso provocó reacciones inmediatas de los gobiemos de Rusia, China, Irán y Francia. El Ministro de Asuntos Exteriores de Francia, H. Vedrine dij, en breve: "Estamos amenazados hoy día por el nuevo simplismo de reducir todos los problemas del mun- 
do a la simple lucha contra el terrorismo. Esto no es serio y no se puede aceptar esta idea. Podemos decirlo y debemos decirlo". En el foro de Nueva York, los representantes de la numerosa delegación árabe lamentaron la ausencia de Yasser Arafat, así como el apoyo unilateral de Estados Unidos a Israel: "Yasser Arafat es el único representante de los palestinos. Esta cólera puede evolucionar en una dirección más peligrosa, a menos que Estados Unidos cambie de actitud y de política respecto al conflicto del Próximo Oriente". De esta manera, se integraron las críticas a la política unilateral de Estados Unidos, en el Próxi-

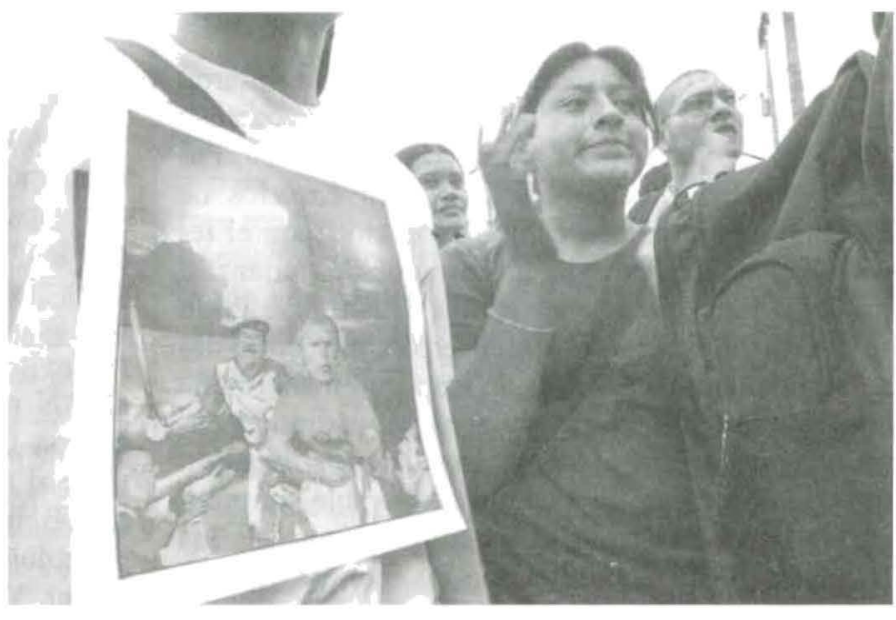
mo y en el Medio Oriente. En Nueva

York se dijo también que "la globalización de la ira se ha acelerado con el rápido crecimiento de las desigualdades sociales" (ECA, 2002, pp. 62-66).

El discurso de Bush tuvo su eco en el Foro Social de Porto Alegre, donde se anunció un futuro que es nuestro presente actual. "El 11 de septiembre ha producido un cambio radical. Luego de los atentados terroristas, que nosotros condenamos, como condenamos todos los ataques contra civiles, en cualquier parte del mundo, el gobierno de Estados Unidos y sus aliados han lanzado una operación militar masiva, en nombre de la guerra contra el terrorismo. La guerra terrorista contra Afganistán tiende a extenderse sobre otros frentes. Es el comienzo de una guerra planetaria permanente para consolidar la dominación del gobierno norteamericano y sus aliados. Esta guerra revela otra cara del neoliberalismo, brutal e inaceptable. En su esfuerzo por proteger los intereses de las grandes compañías, el gobierno norteamericano ha vuelto la espalda con arrogancia a las negociaciones sobre el efecto invernadero (Kioto, 1997), el tratado de misiles antibalísticos (ABM, 1972), a la Convención sobre biodiversidad, a la Convención de Naciones Unidas sobre racismo, y ha demostrado, una vez más, que él resuelve unilateralmente los problemas mundiales". "Después de los atentados (11-S) los temas sociales han sido totalmente dejados a un lado, como si el dolor norteamericano hubiera opacado el dolor de los otros pueblos que sufren" (ECA, 2002, p. 70).

\section{La "economía del terror"}

Dos meses antes, el 17 de noviembre de 2001, se convocó al Grupo de los Veinte (G-20), en
Ottawa, para enfrentar la amenaza de la "economía del terror". "Los ministros de economía de los veinte países pactan medidas para asfixiar la economía del terror". Economía del tenor serían las fuentes de financiamiento que sostendrían la cadena de aclos tertoristas previos y posteriores a los ataques del 11 de septiembre, en Nueva York y Washington. El G-20 se comprometió a "poner en práctica, con carácter de urgencia, las medidas de Naciones Unidas para acabar con el financiamiento del terrorismo, y cada uno congelará los activos de los terroristas y sus asociados, cuyas identidades y cantidades embargadas se notificarán públicamente. Bloquearemos el acceso de los terroristas a nuestro sistema financiero".

Este simple dato es importante, porque muestra el arte del gobierno de Bush para armar y desarmar "alianzas flexibles", a su conveniencia. El G20 había sido creado y convocado en Berlín, en diciembre de 1999, como un grupo consultivo, a raíz de la crisis financiera de 1997-1998: qué se podía hacer para controlar los capitales especulativos, que entraban y escapaban de economías emergentes (como las de Rusia y Brasil), dejándolas en una débil situación financiera. En ese momento, pocas fueron las soluciones presentadas por el G20. Dos años más tarde, "el pánico que el difuso terrorismo ha generado en las grandes potencias occidentales se ha traducido en la gestación de las más amplias alianzas antiterroristas". Quedan dos interrogantes: "Expertos en relaciones intemacionales consideran que el compromiso del G-20 tiene un flanco muy débil, en el frente de los países islámicos. Otro es la ausencia de una fecha límite para cumplir este objetivo" (Realidad, 2002, pp. 7-8). 


\section{Las alianzas flexibles}

A lo largo del año 2002 se hilaron y deshilaron nuevas alianzas flexibles. En el mes de mayo, Bush visitó cuatro países de Europa (Berlín, Moscú, París y Roma), para advertirles y convencerlos de que también ellos son campo propicio para el terrorismo difuso. Nos interesan aquí dos alianzas, pactadas en Moscú y en Roma. Bush y V. Putin firmaron un "pacto contra el terrorismo", que dio a Estados Unidos derecho de inspección sobre una amplia zona, que hasta entonces había sido el patio trasero de Rusia. Ambos mandatarios juzgaron que "la soberanía, la estabilidad durable, la prosperidad y el desartollo democrático futuro de los estados de Asia Central sirven los intereses de Estados Unidos y de Rusia". Allí estaban los casos de los - iterroristas o independentistas?- chechenos y los separatistas de Georgia.

Para avanzar en el camino hacia Bagdad, cabe recordar el "pacto energético", porque en esa región están en juego inmensos recursos petroleros. Ambos jefes de Estado firmaron también un pacto energético, "uniendo sus esfuerzos para desarrollar los vastos recursos energéticos de Rusia y de la región del Caspio". La cooperación energética rusoamericana, en Rusia y en sus zonas fronterizas, "refuerza la soberanía, el bienestar, la cooperación y la integración en la economía mundial de todos los estados participantes". Estados Unidos solo compraba el 0.2 por ciento del petróleo ruso. "Se espera que esta proporción se incremente con los acuerdos de inversiones para el desarrollo y la modernización del sector energético de Rusia, Siberia oriental y el lejano oriente. La inversión se extenderá también a la modernización de la infraestructura portuaria y del transporte del gas y del petróleo. Dos compañías norteamericanas, Chevron Texaco y Exxon Mobil, han firmado contratos para el transporte del crudo, a través del mar Caspio y para la modernización de las plataformas marinas para la extracción del crudo" (Realidad, 2002, pp. 434-435).

\subsection{El final de la guerra fría}

Durante su viaje por Italia, en mayo de 2002, Bush firmó "La declaración de Roma" y se constituyó el "Consejo OTAN-Rusia": "Vivimos en un mundo nuevo... donde nuevas amenazas y desafíos exigen respuestas cada vez más unidas. Por esta razón, los estados miembros de la OTAN y de la Federación de Rusia abrimos un nuevo capítulo en nuestras relaciones". "El pacto con Rusia abre a la OTAN la colaboración frente a nuevas amenazas para las que no está preparada. Ambas partes intercambiarán datos sobre redes terroristas y la formación de unidades de elite, así como sobre sistemas para defenderse de ataques incontrolados con misiles de corto alcance o armas químicas". Bush dijo: "La OTAN es más necesaria que nunca. Tenemos que compartir las informaciones, seguir pistas, evitar que los asesinos actúen y arrestarlos. La OTAN permite eso". A la hora de los brindis, se oyeron frases bonitas. "El pueblo británico ya no teme al ruso, pero los dos tememos al terrorismo", dijo Blair. "Los valores no se defienden solos. No debemos esperar sentados a ser agredidos", agregó Aznar. Y Putin echó la última carta: "No podemos pensar Rusia fuera de Europa” (ibid., pp. 438-440).

Como dijera M. Gorbachov, los grandes estadistas del mundo no han sabido mirarse en el espejo y establecer un compromiso moral, sin caer en el pánico. Cuando uno mira este tramo de la historia desde un poco más adelante, se aprecia que, primero la gran potencia y luego algunos de los aliados, hilan y deshilan alianzas flexibles a su conveniencia, impulsados más por el pánico que por un compromiso moral. En la sala del Consejo de Seguridad de Naciones Unidas, la mayoría de estos pactos son papel mojado. Además, la inseguridad del terrorismo y del contraterrorismo sigue alimentando la inseguridad de la economía. Incluso algunos piensan que este repetido recurso a las amenazas de fuera es una bambalina postiza para ocultar los problemas económicos de dentro. El arzobispo de Canterbury, G. Carei, dijo en el Foro de Nueva York: "El capitalismo plantea hoy un gran interrogante. Es una palabra y es Enron" (ECA, 2002, p. 69) La "economía" se merece un paréntesis por ser una de las "víctimas" de la amenaza de guerra.

\subsection{Construir la confianza}

Por rutina, más que por entusiasmo, se volvió a reunir el Foro económico en Davos, en enero y febrero de 2003, y con otra agenda, el Foro social de Porto Alegre. Había una justificada curiosidad por conocer el lema o logotipo que los organizadores del Foro de Davos presentarían a los asistentes. El nuevo desafío es Building trust, construir la confianza. Algo serio está pasando en nuestro mundo cuando, pese al gran auge tecnológico, crece la inseguridad y no florece la confianza. Además se da la pequeña casualidad de que la palabra trust se 
utiliza también para referirse a las grandes empresas norteamericanas. Los organizadores del Foro de Davos enviaron a los participantes los resultados de un sondeo pasado a 36 mil personas, en 47 países. Le Monde resume los resultados y los comentarios: "Los dirigentes de empresas están masivamente perdiendo la confianza del público. De todas las categorias, los dirigentes de organizaciones no gubernamentales son los más creíbles para la mayoría de ciudadanos (56 por ciento), seguidos por lo líderes de Naciones Unidas y los jefes religiosos (41 y 42 por ciento). A los dirigentes de Estados Unidos se les concede la menor confianza". Y para que las cosas queden claras: "Una mayoría de ciudadanos está en desacuerdo con la dirección en que evoluciona el mundo" (18 de enero de 2003).

Pese a que el presidente Bush presentara (el 7 de diciembre de 2002) un plan de apoyo para la economía de Estados Unidos, los testimonios de los economistas presentes no fueron muy alentadores. Stephen Roach, de Morgan Stanley, afirmó "El panorama para este país es preocupante. El motor del mundo, Estados Unidos, tiene dificultades" y expresó su duda de que la economía estadounidense pueda ofrecer mucho impulso. "Estados Unidos todavía está empantanado en una resaca, después de la burbuja de los noventa, y el crecimiento del año pasado fue patético. Es más, probablemente se estancó en los últimos meses de 2002. Si fuéramos a la guerra con un gran colchón económico, tal vez podríamos salir [del estancamiento]. Si vamos a la guerra con una tasa de crecimiento cero, entraremos en una recesión". Robert Homas, de Goldman Sachs, manifestó las mismas preocupaciones: "Estamos muy bien preparados militarmente, pero no estamos preparados económicamente. Tenemos un gran déficit presupuestario en Estados Unidos. Estamos usando una mayor cantidad de nuestra pólvora presupuestaria para propósitos no estimulantes".

Siendo este un paréntesis económico, pueden leerse otros testimonios similares en el artículo, "Irak en Davos y Porto Alegre 2003" (Realidad, 2003, p. 91), donde también se incluye parte del discurso de Inacio Lula da Silva, en el Foro de Davos. Uno de los economistas que criticó a los dirigentes de la política mundial fue Paul Krugman: "Veo una carencia general de propuestas para hacer algo en el corto plazo". Así resumió las ideas que había desarrollado, en una conferencia, en la Universidad de Georgetown: "Las circunstancias económicas actuales no son tan penosas como en el pe- ríodo que precedió a la gran depresión. No obstante, los principales motores de la economía mundial -Estados Unidos, la zona del euro y Japón- se muestran vacilantes y no puede descartarse el peligro de un grave colapso económico mundial. En las tres regiones, los responsables de la política económica deben tratar de disipar ese peligro adoptando una política monetaria y fiscal más flexible" (Fondo Monetario Internacional, Boletín, 10 de marzo de 2003, p. 54).

Estos y otros testimonios sobre la "átona economía norteamericana" (Krugman) pudieran sugerir a "ciertas mentes" que el gobiemo de Estados Unidos espera utilizar la reconstrucción de Irak para habilitar la reconstrucción de sus propias empresas. Entre estas "turbias mentes" se encuentra Richard Perle, consejero del Secretario de Defensa estadounidense, quien afirmó que Francia no puede asistir al "banquete del club", por no haberse "adherido a él. Es una clara alusión a la reconstrucción de Irak. "En Estados Unidos, otros responsables afirman que los contratos de reconstrucción deben concederse solo a las empresas norteamericanas, contratos estimados en decenas de miles de millones de dólares". Dominique Villepin, Ministro de Asuntos Exteriores de Francia, en conversación con I. Ivanov (Rusia) y J. Fischer (Alemania), había criticado a los responsables norteamericanos, que consideran la reconstrucción de Irak como "un pastel" del cual deben ser excluidos los países que no han tomado parte en la guerra. "La idea de que Irak pueda ser una suerte de El Dorado, un pastel que los estados puedan repartirse, me parece, al mismo tiempo, contraria al sentido común y contraria a la realidad de una población y de un Estado que se hallan hoy en dura prueba" (Le Monde, 6 de abril de 2003).

Lamentablemente, como lo veremos más adelante, los recuadros de Internet nos están presentando, en estos días, las tensiones entre el gobierno de Bush, el Pentágono, Naciones Unidas y la comunidad internacional ante la dolorosa reconstrucción de Irak. Tendremos que esperar unos días, o unas semanas, porque pudiera abrirse alguna brecha entre los jefes de gobierno, que han participado en la guerra y que comienzan a entender que los complejos problemas de posguerra no terminan con el derribo de las estatuas de Saddam Husein (ibid., 7 de abril de 2003). En cualquier hipótesis vale preguntar, ¿qué sentido tienen aquellas palabras: "rezo por la paz, rezo por la paz"? ¿Cuándo y quién puede reconstruir a Estados Unidos? 


\section{Una guerra indeseable y evitable}

El 8 de noviembre de 2002, el Consejo de Seguridad de Naciones Unidas emitió la Resolución 1441 , en la cual conmina al gobierno de Irak, porque no cumple con las condiciones del desarme y por su negligente comportamiento con los inspectores delegados para tal fin por el organismo internacional. La Resolución 1441 incluía severas amonestaciones - de graves consecuencias- para que Irak, en corto tiempo, diera pruebas manifiestas de colaboración activa y abriera las puertas a todas las solicitudes de inspección y diálogo libre con científicos y funcionarios. Estas conversaciones debían ser acompañadas por un proceso de destrucción efectiva de aquellos armamentos que, por su alcance o naturaleza mortífera, contravinieran la Resolución I441.

Había un acuerdo general de que el régimen de Bagdad tenía un historial dictatorial y sanguinario, dentro y fuera de su país - circunstancia a la que algunos gobiernos habían prestado oídos sordos- y que esto pudiera servir de advertencia y norma para otros gobiernos que se comportaban en forma similar, a lo cual también se seguía prestando oídos sordos. Aprobada la Resolución 1441, los informes de los jefes de los inspectores servirían de guía para evaluar el cumplimiento secuencial del gobiemo de Irak. La mayoría de miembros del Consejo de Seguridad deseaba fortalecer las facultades de dichos inspectores, en un tiempo real, a fin de evitar otra salida de consecuencias más graves, la guerra. Durante tres meses, esto generó fuertes tensiones, dentro y fuera del Consejo de Seguridad.

Avanzamos en el camino hacia Bagdad. "La guerra contra Irak no solo es indeseable, sino evitable. Si hasta ahora se había repetido que dependía esencialmente de Saddam Husein, hoy está claro que la última palabra la tiene G. W. Bush y su belicosa administración. Saddam es un dictador sanguinario, en buena medida alimentado en los ochenta por la política de Estados Unidos contra Irán. Su caída para dar paso a un régimen abierto es deseable, pero no a costa de un conflicto que, por muy limpio que se pretenda, producirá, inevitablemente, miles de muertos, acarreará enormes sufrimientos a millones de inocentes y abrirá un futuro impredecible, en la región más caliente del mundo. Saddam es una amenaza que es preciso desactivar, pero resulta desmedido el precio que ha fijado Bush, en forma de primer objetivo de su nueva estrategia de 'guerra preventiva'" (Editorial, El País, 26 de enero de 2003).

Irene Khan, secretaria de Amnistía Internacional, acusó a Estados Unidos y Gran Bretaña de proporcionar información selectiva para fortalecer su caso bélico contra Irak. "En 1988, cuando ocurrió el envenenamiento con gases de kurdos en Halalja, publicamos un informe que el gobierno de Estados Unidos ignoró y no quiso aceptar, en aquel momento, porque entonces Husein era un aliado contra Irán". Se estima que unos cinco mil kurdos murieron, en 1988, a consecuencia de gases químicos (TIMSN-Noticias, 26 de enero de 2003). No es un problema de mala memoria, sino de doble o nula moral, que el gobierno estadounidense insista tan legalmente que Irak cumpla con las resoluciones impuestas por Naciones Unidas, cuando no lo han hecho innumerables veces Israel y su protector incondicional, el mismo gobiemo de Estados Unidos. ¿Con qué autoridad el gobierno de Estados Unidos arrastró a la OTAN a la "guerra humanitaria" de Serbia-Kosovo, y ahora se amarra a una resolución de Naciones Unidas? Su historia no encaja con su moral.

\section{Los informes de los inspectores}

Sin duda, el gobierno Bush se sintió algo decepcionado con los resultados del informe de los inspectores de Naciones Unidas, del 27 de enero. En espera de lo que iba a presentar C. Powell el 5 de febrero, el jefe de los inspectores, Hans Blix, desmintió algunas de las acusaciones vertidas contra Bagdad. "H. Blix ha desmentido, en entrevista al New York Times, que el régimen iraquí está ligado con la red terrorista $\mathrm{Al}$ Qaeda", tal como lo aseveró el presidente Bush. Según Blix, "hay otros esta- 
dos que parecen tener relaciones más estrechas" con Al Qaeda que Irak, citando a Afganistán. Blix, igualmente, estimó que el informe que rindió el 27 enero, ante el Consejo de Seguridad, sobre el desarrollo de las inspecciones, no justifica una gueпra y reconoció que "la diplomacia necesita ser apoyada por la fuerza y las inspecciones por la presión". También desmintió que sus equipos hubiesen descubierto que Bagdad escondía y trasladaba instalaciones ilegales para evitar su inspección, tal como lo afirmó el Secretario de Estado Powell o que agentes secretos iraquíes se hicieran pasar por científicos, tal como lo pudo haber dicho Bush: "Hay algunos casos de personas que hemos interogado que parecen no saber gran cosa, pero esto no ha sido frecuente".

Blix puso en duda la teoría de Bush, según la cual una guerra pudiera evitar un atentado a escala mayor, utilizando armas biológicas, químicas o nucleares. "El mundo ha progresado mucho", dijo Blix, para quien "la seguridad mundial es hoy más sólida que en tiempos de la guerra fría. Creo que sería terrible que todo esto termine con el uso de la fuerza armada, y deseo que este proceso de desarme se prosiga por la vía pacífica". Según el New York Times, Blix hizo lo posible para "disipar la impresión de que su informe se utilizase para apoyar la campaña del gobierno [Bush] y ganar el apoyo de la comunidad internacional, a favor de una guerra para desarmar a Saddam Husein". "No he adaptado mi informe a los intereses políticos o a las expectativas de Bagdad, ni de Washington, ni de ningún otro país". Lo que sí añadió fue: "No he solicitado proseguir las inspecciones, porque no he visto un cambio de actitud de parte de Irak, a la cual he reprochado su falta de cooperación activa" (Le Monde, 1 de febrero de 2003). Esta última frase es importante para entender la propuesta del "pacto franco-alemán", que veremos más adelante.

Estados Unidos logró, con sus amenazas, que Bagdad se plegara a recibir a los inspectores de Naciones Unidas. "El peligro es que la dinámica de la amenaza lleve inexorablemente al uso de la fuerza. Algo que parece irrebatible cuando se observa el formidable despliegue aeronaval y terrestre de Estados Unidos en el golfo, que, a mediados de febrero, rondará los 150000 hombres y media docena de portaaviones con sus grupos de combate. Un peligro que se incrementa si las razones de Bush para golpear, que vienen desde antes del 11$S$, incluyen secretamente el control del petróleo iraquí y el rediseño del mapa político de Asia Central. El ala más belicista republicana viene dibujando ante la opinión pública el paisaje de la posguerra como el de una región transformada y modernizada por la fuerza de las armas" (El País, 26 de enero de 2003). Estas afirmaciones no son descabelladas, si se toman en cuenta los "pactos político y energético", firmados en Moscú, en mayo de 2002, por Bush y Putin para ejercer control político y económico sobre Eurasia.

Powell dio a entender, en el Foro económico de Davos, que Estados Unidos se reservaba el derecho de atacar sola a Irak, si el Consejo de Seguridad y los otros gobiernos renunciaban a zanjar el problema del desarme de Bagdad. "El multilateralismo no puede servir de excusa para la inactividad. Nosotros tratamos estos problemas pacientemente y de manera precisa con nuestros amigos y aliados... Si [el régimen iraquí] no se desarma en esta ocasión, será desarmado después. No nos resistimos a hacer la guerra, si ésta es la única manera de arrancar a Irak sus armas de destrucción masiva". Powell dio a entender que Saddam Husein tiene "claros contactos con grupos terroristas, entre ellos Al Qaeda". Un signo del endurecimiento de Washington fue que estrategas del Pentágono se inclinaban por la opción nuclear para destruir los centros de mando subterráneos de Saddam Husein: "Estados Unidos se reserva el derecho de defenderse y defender a sus aliados con todos los medios necesarios" (Le Monde, 26 de enero de 2003).

En su discurso al Congreso, el 28 de enero 2003, Bush hizo una declaración informal de gue- 
тra: "El mundo ha esperado doce años para que Irak se desarme. Estados Unidos no acepta que siga creciendo una amenaza a nuestra nación, a nuestros amigos y a nuestros aliados. Vamos a consultar, pero que no haya malentendidos; si Saddam Husein no se desarma completamente, por la seguridad de nuestra gente y por la paz del mundo, nosotros vamos a liderar una coalición para desarmarlo". En su discurso, que fue etiquetado como "doméstico" por la misma Casa Blanca, "Bush volvió a subrayar el carácter unilateral de su gobierno y la dicotomía de la política exterior con la que desde enero de 2001 ha querido manipular el mundo". Entre aplausos del ala republicana, Bush hizo una declaración informal de guerra: "Enviar a la batalla a los estadounidenses es la decisión más profunda que puede tomar un presidente; las tecnologías de guerra han cambiado; no los riesgos y sufrimientos de la guerra. A los estadounidenses valientes que desafían los riesgos (les digo) que no hay victoria exenta de sufrimiento".

Al día siguiente, los inspectores de armas de Naciones Unidas informaron que "después de 60 días de investigaciones en Irak podían concluir con certeza que Husein no tiene en vigencia programas de desarrollo de armas químicas, pero que no hay certeza de que tenga armas químicas o biológicas, por lo que solicitaron más tiempo para corroborarlo o desmentirlo...". La unilateralidad de la Casa Blanca fue evidente y se postró por encima no solo de la comunidad internacional, sino de los estadounidenses y del Congreso, quienes se oponen a la guerra. Bush manifestó con claridad su dicotomía de la política exterior, dándole un trato bélico al caso de Irak, que no tiene armas nucleares para

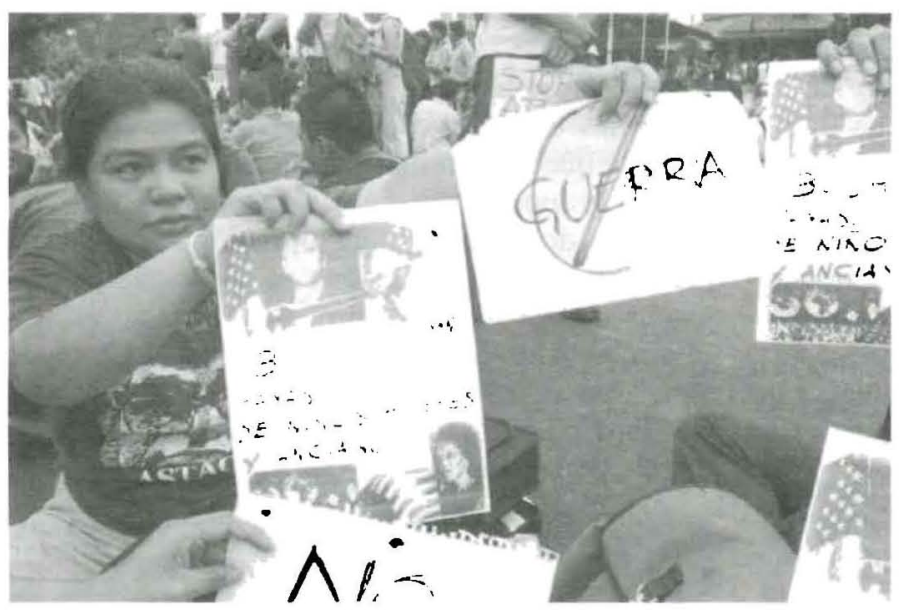

poder atacar directamente a Estados Unidos, y diplomático al de Corea del Norte que, en desafío a Washington, declaró que sí tiene armas atómicas y que quiere más" (TIMSN-Noticias, 29 de enero de 2003).

\section{Se abre la brecha en el Consejo de Seguridad}

En los meses de enero y febrero se abrió la brecha y creció la tensión entre los gobiernos que desean evitar a toda costa una guerra destructiva para la población de Irak y quienes presionan con la solución de la guerra para doblegar la resistencia de Saddam Husein, poniendo fin a la presunta amenaza a la seguridad de Estados Unidos y los países aliados. De acuerdo a informes recibidos, había patentes conexiones entre Saddam y terroristas entrenados y albergados en Irak, incluso miembros de Al Qaeda. A finales de febrero se acercaron a 200000 los miembros de los ejércitos combinados de Estados Unidos e Inglaterra.

El 15 de febrero de 2003, los diarios publicaron la resolución presentada por los gobiernos de Estados Unidos, Inglaterra y España, declarando que "Irak no ha aprovechado la última posibilidad ofrecida con la resolución 1441 , y que, en consecuencia, quedaba legitimada la guerra preventiva" (Le Monde, 25 de febrero de 2003). De esta forma, los gobiernos de estos tres países se oponían radicalmente al llamado "pacto franco-alemán", que buscaba alternativas pacíficas con miras a evitar la guerra, en Irak. De acuerdo al Ministro de Asuntos Exteriores de Francia, Dominique Villepin, no se trataba, propiamente, de un plan de desarme de Irak, sino de apoyar a los inspectores de Naciones Unidas con medios complementarios, dado que la mayoría de los miembros del Consejo de Seguridad apoyaba la idea de "explorar hasta el fin" la vía pacífica para desarmar a Irak.

El "pacto franco-alemán" consistía en duplicar o triplicar el número de inspectores de Naciones Unidas en Irak, estableciendo un cuerpo especializado, encargado de mantener bajo vigilancia los sitios y las zonas ya controladas. Reforzar sensiblemente la capacidad de observación y recogida de informaciones, en territorio iraquí. Al vuelo de los $U 2$ estadounidenses sobre suelo iraquí, a lo cual Irak debía plegarse de inmediato, se añadirían los Mirages IV fran- 
ceses, equipados para misiones de observación. Crear un centro de coordinación y depuración de información, capaz de proporcionar, en tiempo real, los datos que necesitase el jefe de la inspección, Hans Blix, y el director de la Organización de la Energía Atómica, Mohamed El Baradel. Además, estos últimos contarían con un coordinador permanente de Naciones Unidas para desarmar a Irak (El País, 9 de febrero de 2003; Le Monde, 9 de febrero de 2003).

Esta propuesta generó fuertes tensiones entre Estados Unidos y Francia. El Ministro de Defensa, Donald Rumsfeld, invitó a los europeos "a unirse a la coalición más importante de la historia", advirtiendo a Francia y Alemania (a quienes llamó la "vieja Europa") que peligraban "aislarse ellos mismos, más que aislar a Estados Unidos", al oponerse a una intervención inmediata. La respuesta de un delegado francés fue que "hablar de sus aliados, implica el diálogo y el respeto de los otros socios. Es saber consultarse para llegar a un consenso. No vale decir: mi idea es necesariamente la buena y todos los que no están de acuerdo conmigo quedan relegados y excluidos". Esta respuesta refleja lo que venía siendo el comportamiento de varios miembros del gobiemo de Estados Unidos, su unilateralidad y su hilado y deshilado de alianzas flexibles con países socios y aliados (Le Monde, 9 de febrero de 2003).

\section{Premios Nobel estadounidenses en contra de un ataque unilateral}

Varios representantes del mundo científico de Estados Unidos se opusieron a que su presidente ordenase la invasión a Irak "sin contar con el respaldo de Naciones Unidas". El 28 de enero de 2003, 41 científicos estadounidenses publicaron un manifiesto, en el cual exponen su rechazo a "una guerra preventiva contra Irak desprovista de un amplio apoyo internacional". Uno de los firmantes es el general retirado Norman Schwarzkoft, quien dirigió la coalición vencedora en la guerra del golfo de 1991. En esa ocasión, Irak había invadido Kuwait y, por lo tanto, había una razón intemacional para sacar a Saddam del país invadido, aunque la guerra no tuvo nada de humanitaria y se utilizaron armas bactereológicas. El general Schwarzkoft, amigo del presidente Bush (padre), declaró que, en su opinión, "Estados Unidos debería esperar y ver qué consiguen los inspectores" y lamentó la falta de "un poco de prudencia", en la estrategia de Bush hijo. "Francamente, algunas de las cosas que dice Rumsfeld me ponen muy nervioso. Cuando habla el Secretario de Defensa parece despreciar al ejército y parece disfrutar con la idea de entrar en guerra".

El documento lo firman dos físicos, $\mathrm{H}$, Bethe $\mathrm{y}$ N. Ramsey, que trabajaron, en 1945, en el programa ultra secreto de la primera bomba atómica. Firma el químico W. Kohn, asesor científico del Pentágono, y Ch. Towven, especialista en ojivas nucleares. Firman economistas como F. Modigliani y L. Klein, y médicos como L. Ignarro y $\mathbf{H}$. Warmus. "Los abajo firmantes" - dice el documento- "se oponen a una guerra preventiva contra Irak desprovista de un amplio apoyo internacional. Las operaciones militares contra Irak pueden ciertamente conducir a una victoria contundente en poco tiempo. Pero la guerra se caracteriza por la sorpresa, la pérdida de vidas humanas y los resultados imprevistos. Incluso con una victoria creemos que las consecuencias médicas, económicas, ambientales, morales, espirituales, políticas y legales de un ataque preventivo podrían erosionar, en lugar de proteger, la seguridad y la influencia de Estados Unidos en el mundo".

La crítica de este representativo grupo de científicos se basa en razones "ex ante", ser una "guerra preventiva" y sin consenso internacional, y en los múltiples efectos "ex post" sobre la población de Irak y sobre el descrédito de Estados Unidos ante la opinión mundial. Sin embargo, este documento en poco o en nada perturbó la "conciencia" del gobiemo de Bush. El senador demócrata J. Biden atacó duramente su política exterior, "por su doble lenguaje, que hace que nuestros aliados se pregunten por qué negociamos con Corea del Norte, que tiene armas nucleares, y queremos invadir Irak, que no las tiene; por una doctrina de ataques preventivos que India o Pakistán pudieran acabar invocando para atacarse mutuamente; por no per- 
manecer lo bastante en Afganistán, lo que hace sospechar que también abandonaremos Irak a su suerte tras derrocar a Saddam Husein, y, finalmente, por promover con su lenguaje la mayor oleada mundial de antiamericanismo de los últimos treinta años" (El Pais, 29 de enero de 2003).

Aunque se trata de un documento personal, la carta abierta de Norman Birbaum, profesor emérito de Georgetwon, refleja el sentimiento y el enojo de millones de ciudadanos en todos los continentes y es, al mismo tiempo, una respuesta anticipada a los discursos de Bush el 6 y 16 de marzo. Es una carta abierta a los primeros ministros de España, Dinamarca, Hungría, Italia, Polonia, Portugal, Reino Unido y república Checa.

Su declaración de solidaridad con la política del gobierno estadounidense hacia Irak plantea más preguntas de las que responde. Solidaridad con nuestro gobierno no es lo mismo que solidaridad con nuestro pueblo. Dentro de sus propios países la mayoría rechaza la política estadounidense con respecto a Irak. Los sondeos de opinión en Estados Unidos reflejan una nación profundamente dividida. La constemación, la duda y la oposición a una guerra contra lrak están aumentando con rapidez. En estas circunstancias, su Ilamada a la 'unidad' con Estados Unidos tiene un tono curiosamente ritualizado...

Los preparativos del Gobierno Bush para la guema incluyen restricciones draconianas de los derechos de los residentes o visitantes árabes o musulmanes en Estados Unidos. Quienes respaldan al presidente han organizado una campaña de difamación e intimidación contra aquellos ciudadanos que manifiestan su disensión. Grotescamente, el plan milenarista del gobierno de Bush para democratizar a Oriente Próximo nunca se ha debatido en el Congreso, ni en la nación. En ambas orillas del Atlántico, nuestras culturas democráticas manifiestan profundas fallas. Declaran ustedes que el sistema de derecho es un componente primordial de nuestra herencia común. El presidente Bush sostiene que nuestro país tiene derecho a eliminar enemigos en potencia mediante ataques preventivos. La proclamación del derecho de ataque preventivo por parte de una nación contra otra es un asalto definitivo contra la dolorosamente construida estructura del derecho internacional. Es una invitación a que otros países sigan su ejemplo. Estados Unidos ya ha transgredido el derecho internacional con el trato dado a los prisioneros que ha hecho en Afganistán o que han sido capturados por gobiernos aliados en otras partes.

Aceptan ustedes, con pasmosa tranquilidad, la afirmación de que "el régimen iraquí y sus armas de destrucción masiva representan una clara amenaza para la seguridad mundial. Repiten algo que no es más que una ficción de la Casa Blanca, que Irak respalda a Al Qaeda. No hay pruebas convincentes de ninguno de los dos argumentos. Tratan ustedes la obsesión del presidente Bush con Irak como algo racional. Las amenazas para la seguridad mundial, que suponen la creciente brutalidad del gobiemo israelí en Palestina, el conflicto entre India y Pakistán, el programa de armamento de Corea del Norte, no parecen preocuparles excesivamente. Las amenazas mayores como el hambre, la enfermedad y la pobreza en el mundo no merecen una mención por su parte. Mientras tanto, con una indiferencia bastante convincente por las consecuencias, están ustedes dispuestos a respaldar a Estados Unidos, en el inicio de una conflagración en Oriente Medio. Nada parece importarles más a ustedes que evitar un conflicto con el gobierno actual de Estados Unidos. Es difícil creer que esto vaya en consonancia con la dignidad de sus pueblos o con una amistad duradera con Estados Unidos. Lo que nos honraría a todos sería la abierta expresión de una disensión y no la ansiosa demostración de fidelidad. En este sentido, las opiniones públicas de sus países son mejores amigas de nuestra nación que sus dirigentes" (El País, 9 de febrero de 2003).

Esta carta de Norman Birbaum es una crítica anticipada a los discursos del 6 y 16 de marzo del presidente Bush.

\section{Bush se dirige al pueblo norteamericano}

En vísperas del 7 de marzo, cuando el jefe de inspectores Hans Blix presentara su informe al Consejo de Seguridad, el presidente Bush, en conferencia de prensa, anunció "la última fase de la diplomacia" para solucionar el problema iraquí. "Es la hora en que todos muestren sus cartas y que el mundo sepa cuál es su posición respecto a Saddam. En pocos días resolveremos este problema en el Consejo de Seguridad". Cada uno de los miembros debe ser responsable. "Estoy convencido de que el pueblo norteamericano comprende que, cuan- 
do se trata de nuestra seguridad, si debemos actuar vamos a actuar y no necesitamos realmente la aprobación de Naciones Unidas para hacerlo. No necesitamos el permiso de nadie. No dejaré al pueblo norteamericano a merced de un dictador iraquí y de sus armas". Los atentados del 11 septiembre han mostrado que "el campo de batalla" será en adelante Estados Unidos. La salida de la guerra es que Saddam "abandone el país". Dato esclarecedor es que Bush dijera en esta conferencia de prensa que él rezaba todos los días por la paz y, si estallara la guerra, él rogaría por la seguridad de las tropas norteamericanas y por la seguridad de los iraquíes inocentes. "Mi fe me sostiene porque yo oro cada día. Pido que ella me guíe y me dé sabiduría y fuerza. Rezo por la paz. Rezo por la paz". (Le Monde, 08 de marzo de 2003).

En un editorial posterior de Le Monde, titulado "Dios y Norteamérica", se recuerda que Bush dice que reza todos los días y sus discursos terminan con el célebre estribillo: "Dios bendiga a América". Todas las reuniones del gabinete de su gobierno se inician con una oración que prepara, por turno, cada uno de los ministros. El Congreso ha instituido "un día de humildad, de oración y de ayuno por el pueblo de Estados Unidos". Esta práctica, aparentemente religiosa, dice el editorial, puede leerse de otra manera, en el actual escenario de la guerra: "Más allá de todos los principios [religiosos] esta continua invocación a Dios peligra transformar, a los ojos de millones de musulmanes, el conflicto entre la coalición anglo-americana y los iraquíes en una 'nueva cruzada', en un choque de civilizaciones y de religiones con devastadoras consecuencias más allá de la religión. En el mismo momento en que se tomó la decisión de un día de oración en Estados Unidos, un imán iraquí, armado con un kalachnikov, invocaba a Alá para que viniera a sacar de la tierra árabe a los infieles (Le Monde, 29 de marzo de 2003).

Después de la conferencia tripartita, en las islas Azores, donde se reunieron el presidente Bush y los jefes de gobiemo Blair y Aznar, se precipitó, de manera unilateral, la decisión de iniciar la gueта. Ese 16 de marzo, Bush dio a entender que todavía quedaba un pequeño espacio para la diplomacia. "El lunes [17 de marzo] será el día en que se sepa si todavía es posible una solución diplomática para Irak. El mundo está ante unos días cruciales. Mañana será el momento de la verdad. El régimen iraquí tiene que desarmarse o será desarmado por

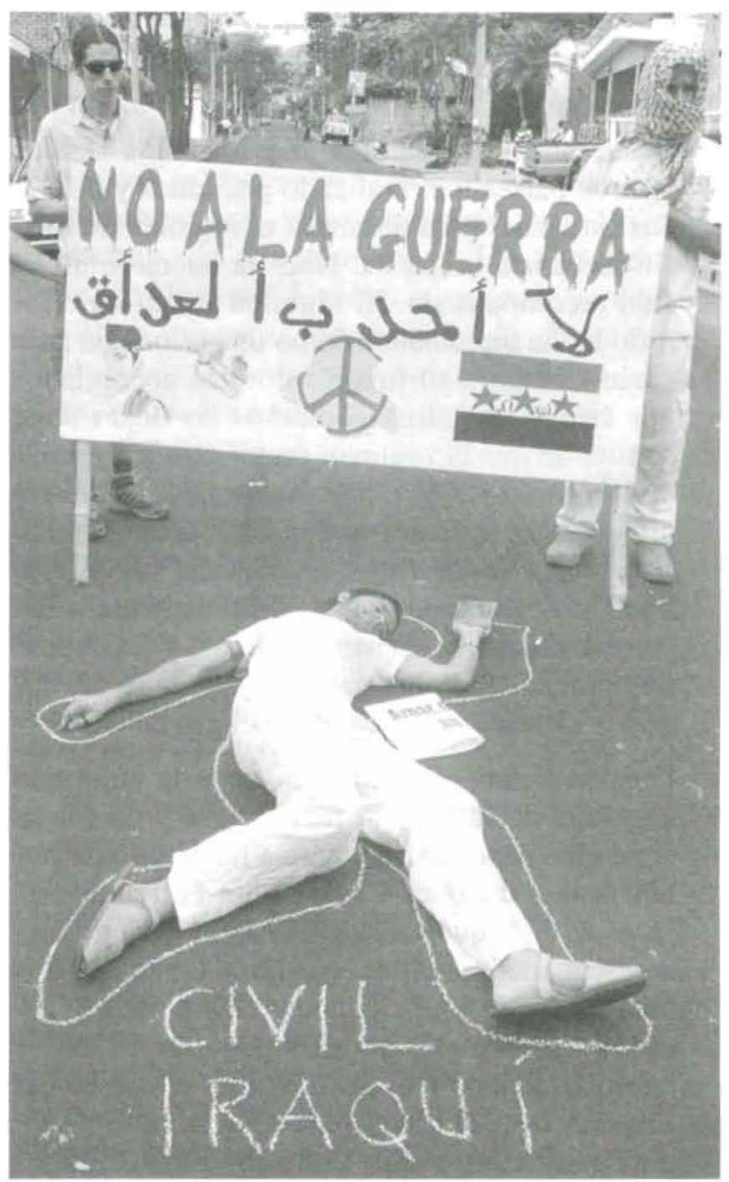

la fuerza". Blair y Aznar avalaron la decisión, porque Saddam es el único responsable. Sin consulta. ni aprobación del Consejo de Seguridad, el presidente Bush dio por cancelada la vía diplomática y, en una alocución televisada, exhortó a "Saddam y a sus hijos a abandonar el poder en cuarenta y ocho horas. Su rechazo conducirá a un conflicto militar, que comenzará en la fecha que vamos a señalar". Al mismo tiempo, Bush recomendó a todos los periodistas e inspectores de Naciones Unidas abandonar Irak sin esperar más.

El discurso de Bush, tal como Norman Birbaum y otros expertos de ambos lados del Atlántico señalaron, está plagado de inexactitudes, alucinaciones personales, modificaciones de la verdad, exaltación del espíritu pacifista de su gobiemo e, incluso, acusación de irresponsabilidad a algunos miembros del Consejo de Seguridad. Es una alocución de quince minutos al pueblo estadouniden- 
se, que, naturalmente provocó, y seguirá provocando reacciones encontradas, en cada oyente o lector. He aquí algunos párrafos.

Desde hace más de diez años, Estados Unidos y otros países han realizado pacientes y honrados esfuerzos para desarmar el régimen de Irak, sin recurrir a la guerra. Nuestra buena fe no ha sido recompensada. El régimen iraquí ha utilizado la vía diplomática como una estrategia para ganar tiempo a su favor. Informes acumulados por éste y por otros gobiernos no dejan duda alguna de que el régimen iraquí posee y esconde armas mortales jamás imaginadas. Este régimen ya ha utilizado armas de destrucción masiva contra los pueblos vecinos de Irak y contra el pueblo iraquí. Odia profundamente a Estados Unidos y a nuestros amigos, y ha ayudado, entrenado y albergado a terroristas, incluidos agentes de $\mathrm{Al}$ Qaeda. El peligro es claro.

Estados Unidos de América tiene la autoridad soberana de utilizar la fuerza para proteger su seguridad nacional... América ha procurado trabajar con Naciones Unidas para enfrentar esta amenaza, porque queremos arreglar el problema de manera pacífica. Nosotros creemos en la misión de Naciones Unidas... Durante los pasados cuatro meses y medio Estados Unidos y nuestros aliados han trabajado en el marco del Consejo de Seguridad para aplicar las anteriores resoluciones del Consejo. Pero algunos miembros permanentes del Consejo de Seguridad han anunciado que opondrán su veto a cualquier resolución que obligue al desarme de Irak. Estos gobiernos comparten nuestro análisis del peligro, pero no muestran determinación para enfrentarlo. Sin embargo, muchas naciones tienen la determinación y la fuerza moral para enfrentar esta amenaza a la paz, y se está formando una amplia coalición para aplicar las justas demandas del mundo. El Consejo de Seguridad de Naciones Unidas incumplió sus responsabilidades $y$, por lo tanto, nosotros vamos a asumir las nuestras...

En este discurso, Bush exhorta a extranjeros, periodistas e inspectores de Naciones Unidas a abandonar Irak lo antes posible "por su propia seguridad". Comunica al pueblo iraquí que escuchen la radio y su mensaje para que entiendan que la posible campaña militar es contra los hombres sin fe y sin ley, que dirigen al país. Proporcionará alimentos, medicamentos y ayudará a reconstruir la nación. "El día de su liberación está cerca". Bush invita a los soldados a dejar entrar pacíficamente a las fuerzas de la coalición y a no quemar los pozos de petróleo, la gran riqueza de su país. Dirigiéndose al pueblo estadounidense, agrega que se han tomado mayores medidas de seguridad en los aeropuertos, en las costas periféricas y en otros lugares de equipamiento en Estados Unidos. Los posibles terroristas lo pagarán caro. "Estados Unidos, junto con otros países, va a trabajar para hacer progresar la libertad y la paz en la región... Que Dios continúe bendiciendo a Norteamérica" (Le Monde, 18 de marzo de 2003).

Este discurso de Bush está plagado de inmoralidad. Es inmoral dejar con la palabra en la boca y no escuchar los informes presentados a su tiempo por los jefes de los inspectores de Naciones Unidas. Es inmoral acusar a los autores del "pacto franco-alemán" de oponerse al desarme de Irak, cuando pretendían fortalecer el papel de los inspectores y llegar, por la vía pacífica, "al desarme de Irak". Es inmoral acusar de falta de responsabilidad y de fuerza moral a los miembros del Consejo de Seguridad que buscaban, hasta el último momento, evitar una "guerra preventiva", con todas las consecuencias anunciadas por los premios Nobel estadounidenses. Es inmoral, como dijo Norman Birbaum, acusar a Irak de hechos que no estaban realmente comprobados. Es inmoral exaltar el espíritu pacifista del gobiemo de Estados Unidos, cuando desde comienzos de febrero ya había fondeado sus portaaviones y ejércitos, en las costas adyacentes a Irak. Es inmoral hablar de una amplia coalición del mundo, cuando en los meses de febrero y marzo, en todas las esquinas del mundo, millones de manifestantes han gritado No War. Es inmoral visitar al Papa y cerrar los oídos a sus palabras. "Quien decida que todos los medios pacíficos de los que dispone el derecho intemacional se han agotado, tendrá que asumir una grave responsabilidad ante Dios, ante su propia conciencia y ante la historia".

El presidente Chirac insistió en que el desarme de Irak era necesario, pero "eso no justifica una decisión unilateral de recurrir a la guerra". El uso de la fuerza es "una decisión unilateral y contraria a la voluntad del Consejo de Seguridad. Es una decisión grave. Irak no representa actualmente una amenaza inmediata que justifique una guerra inmediata". El nuevo presidente de China, Hu Jintao, manifestó a Bush que "la posición de China siempre ha sido consistente; quiere que no haya una 
guerra en Irak y que Saddam Husein elimine las armas de destrucción masiva. China siempre apoya una solución política, en el seno de Naciones Unidas". Putin lamentó, en conversación telefónica con Bush, "la solución del ultimátum" y le manifestó su disgusto, porque los esfuerzos diplomáticos para resolver la crisis "no hayan alcanzado un compromiso recíprocamente aceptable"

Schroder manifestó que "la importancia de la amenaza que emana del dictador iraquí no justifica una guerra y la muerte de miles de inocentes". Para Schroder, la resolución 1441 de Naciones Unidas, que pide a Irak destruir las armas, de lo contrario, habría "graves consecuencias", no incluye como objetivo desbancar al régimen, "por indeseable que ello sea". La liga árabe rechazó el ultimátum de Bush: "Semejante ultimátum es inaceptable para la Liga Arabe, porque todo el mundo reconoce que Irak ha cooperado con los inspectores para aplicar la resolución 1441". Tom Daschle, jefe de la minoría demócrata, en el Senado, declaró: "Me entristece que este presidente haya fracasado tan miserablemente en la diplomacia, que ahora estamos forzados a la guerra" (El País, 18 de marzo de 2003). Sería inmoral la guerra si, como lo afirma Paul Harris, economista de la Universidad de Columbia, la razón de esta "guerra preventiva" ha sido que el gobierno de Irak ha pasado todos sus petrodólares a la zona del euro. Si este ejemplo fuera imitado por el resto de miembros de la OPEP, "el déficit record de cuenta corriente y el status de Estados Unidos como la principal nación deudora" se vería gravemente afectado ("¿Qué pasaría si la OPEP se cambia al euro?", Reflexión y liberación, 56, 20022003, pp. 29-31).

\section{0. ¿Fracaso de Naciones Unidas?}

Se trata más de una pregunta que de una respuesta, aunque nos inclinamos por afirmar que Naciones Unidas no ha fracasado y esperamos que salga fortalecida, porque es una de las pocas instancias mundiales que trata de defender la moralidad en la guerra y la equidad en la economía global. En la Cumbre del Milenio, en septiembre de 2000, Kofi Annan dijo: "Hay que reinventar $\mathrm{Na}$ ciones Unidas". La razón no es solo que, desde su fundación, se haya duplicado la población mundial, sino que se han cuadruplicado los conflictos armados, los exterminios étnicos, los acuerdos no ratificados (Kioto, Corte Penal Internacional...) y "el malestar en la globalización".
Uno de los ejes que se quería reestructurar en esa cumbre era la "composición del Consejo de Seguridad" para que fuera más representativo de la seguridad mundial. Hubo resistencias. Los primeros que se opusieron fueron los cinco miembros permanentes que, entre paréntesis, son los cinco países que más exportan armas. Los 188 representantes de Naciones Unidas, además de su discurso de cinco minutos, firmaron la Declaración del Milenio, aunque no todos habían leído el texto $\mathrm{y}$, por lo tanto, desconocían los compromisos que estaban adquiriendo. Los "valores y principios" de la Declaración del Milenio, reflejados en los grandes temas - seguridad, desarrollo, medio ambiente, derechos humanos, fortalecimiento de Naciones Unidas, etc. - siguen siendo válidos y su concreción es cada vez más urgente. Esta declaración tiene mucho de "buena noticia". ("Entorno económico mundial", Cuaderno de cátedra, UCA Editores, 2003, pp. 183-195).

En el sondeo hecho con ocasión del foro económico de Davos de 2003, los jefes de Naciones Unidas aparecían entre los mejor evaluados, en cuanto "creadores de confianza". Por lo tanto, quienes han irrespetado a Naciones Unidas son lo contrario. Por añadidura y con una gran tenacidad, los dirigentes de Naciones Unidas organizan cada año una serie de cumbres mundiales; por citar algunas: Economía y desarrollo, en Bangkok; Cumbre del Milenio, en Nueva York; El alivio de la pobreza, en Monterrey; El desarrollo sostenible, en Johanesburgo... Hay que agregar los análisis anuales sobre "desarrollo humano", en tantas esquinas del mundo. Al igual que la mayoría de las instituciones humanas, Davos tiene deficiencias evidentes y ha reconocido olvidos y fracasos, en especial, negligencia para detener horribles genocidios, en África y Asia Oriental; pero aun así es uno de los rescoldos donde se mantienen principios de moralidad y humanismo. 'El mundo estará más seguro si sabe que Naciones Unidas puede intervenir cuando está amenazado por una destrucción masiva... Pero la acción global tiene que comenzar en algún sitio, y si no es en Naciones Unidas, ¿dónde?". dijo Kofi Annan. La pregunta del Secretario General es una respuesta a quienes piensan que esa institución ha fracasado y está desautorizada. Más bien, quedan desautorizados quienes la han irrespetado.

Si hoy día se habla de "otro Fondo Monetario Internacional" y de "otro Banco Mundial", pode- 
mos llegar a una solución similar: "hay que reinventar Naciones Unidas". Puestos a hacer propuestas, ¿no se pudiera aprovechar la oportunidad de la reconstrucción de Irak para trasladar a esa "tierra de los profetas" la torre de Naciones Unidas, desde donde se tendría otra visión del mundo?

\section{Grietas en la reconstrucción de Irak}

No es que se estén abriendo grietas en los nuevos edificios de Bagdad, porque hasta el 11 de abril nada se había construido. Seguían los enfrentamientos, en la zona petrolera del norte, con una masiva afluencia de kurdos, llegados de Turquía; seguía el pillaje incontrolado, que la Cruz Roja Intemacional intentó controlar; seguían las grandes ciudades $\sin$ luz y $\sin$ agua y los abarrotados hospitales sin recursos para atender a los heridos, y seguía la incógnita del número de muertos, refugiados y exilados. $Y$ esperamos que ya no sigan apareciendo, en nuestros diarios matutinos, las fotografías del exuberante armamento de la "coalición". Sin embargo, ya están apareciendo las grietas entre los "posibles actores" de la reconstrucción y del reparto del "botín de la reconstrucción". Habrá que esperar un liempo para que

Es inmoral exaltar el espíritu pacifista del gobierno de Estados Unidos, cuando desde comienzos de febrero ya había fondeado sus portaaviones y ejércitos, en las costas adyacentes a Irak.

Es inmoral hablar de una amplia coalición del mundo, cuando en los meses de febrero y marzo, en todas las esquinas del mundo, millones de manifestantes han gritado No War. se arme un mosaico con las piezas todavía sueltas, por miedo a romper alianzas o por la negativa a formarlas.

Blair quería que Naciones Unidas apoyara al futuro gobierno de Irak, pero no se expresó claramente, ante el Parlamento inglés, sobre el cómo, el cuándo y sobre qué aspectos de la reconstrucción (El País, 3 de marzo de 2003). Tampoco se esclareció mucho la interrogante que dejó la reunión de Blair con Bush, en Irlanda: "Naciones Unidas se integrarían desde un cierto punto de vista". Nadie aclaró cuál era el punto de vista, porque Bush dio a entender que se confiaba al Pentágono, y no al Departamento de Estado, la responsabilidad de la ayuda humanitaria estadounidense y la reconstrucción de Irak (Le Monde, 7 de abril de 2003). Más compleja aún parece ser la tensión dentro del gobierno de ese país, por la propuesta alianza con iraquíes llegados del exterior, presididos por Ahmad Chalabi —quien no goza de la confianza de Powell ni de la $\mathrm{Cia}-$, y con etnias residentes en Irak. Washington está de acuerdo en que el proceso de "estabilización" se lleve a cabo bajo la égida de la coalición anglo-americana. Pero Powell propone que también la OTAN participe en el mantenimiento de la paz y de una "segura estabilización". Pero esta propuesta no cuenta con el aval de Francia y Alemania, que pudieran rechazar un compromiso para no legitimar la intervención de Estados Unidos e Inglaterra (Le Monde, 8 de abril de 2003). No parece fácil armar el mosaico.

Además, para entendidos y no entendidos, hay conductas que huelen a pillaje y a podrido. "La Comisión Europea considera ilegal que Estados Unidos intente excluir a Francia, Alemania y también a Rusia y Siria del proceso de reconstrucción de Irak, y así se lo ha hecho saber a la Casa Blanca": Bruselas considera que con ello "se violan flagrantemente las reglas de la". Se abre así una grieta política y comercial entre Europa y Estados Unidos. "Bruselas afirma que, si finalmente se materializa la exclusión, se considerará como una 'violación flagrante' de los acuerdos de la Organización Mundial del Comercio y no descarta la apertura de la vía contenciosa en Ginebra... Tenemos que asegurarnos de que Estados Unidos cumple las reglas, pero tampoco deseamos que se abra un nuevo frente de litigio con dicho país" (El País, 11 de abril de 2003).

Si el río suena, agua lleva. El gobierno español reconoció que había negociado con Estados Unidos su participación en la reconstrucción de Irak (El País, 7 de abril de 2003). El reverso tiene la misma tonalidad. "Francia debe 'pagar un precio' por su oposición a la intervención militar norteamericana en Irak y sobre todo por su veto a un apoyo de la OTAN a Turquia", advirtió Paul Wolfowitz, segundo del Ministerio de Defensa. "El comportamiento de Francia ha sido en cierto modo nefasto para la OTAN y creo que Francia debe asumir las 
consecuencias, no solo con nosotros, sino también con otros países que sienten lo mismo" (Le Monde, 1 I de abril de 2003).

El 11 de abril se reunieron, en San Petersburgo, Putin, Chirac y Schoder, previas reuniones bilaterales y repetidos contactos telefónicos de Chirac con Blair. Los corresponsales hablan de ir delineando acciones de posguerra, de manera especial el papel de Naciones Unidas. El objetivo es convencer a Bush, vía $T$. Blair, para que no deje en manos de los "duros" del Pentágono el proceso de la reconstrucción y estabilización de Irak. De visita en Alemania, Putin se mostró complacido por "la caída del régimen de Saddam Husein", lamentó la destrucción y las víctimas de la guerra. "Es algo bueno que el régimen de Saddam haya caído. La caída de un régimen dictatorial es un dato positivo. Pero son malos los medios puestos por obra, las destrucciones y los muertos. No defendíamos a Saddam Husein, pero dijimos que no convenía derocarlo por la fuerza. El 80 por ciento de los países del mundo está en situación similar a Irak. ¿Se va a declarar la guerra a todos? Ciertamente, no. Eso debe hacerse desde el interior; solo cada país tiene el derecho a determinar 'su régimen político'. Nuestras naciones deben hacer lo posible para conservar la estabilidad del derecho internacional, que se asienta en el poder superior de Naciones Unidas, y nuestro objetivo principal es encauzar lo antes posible el ordenamiento iraquí dentro del marco de esta institución".

Chirac declaró, en una reunión con Putin, que "La situación intemacional justifica este encuentro, se trate de la situación de Irak, o del Medio Oriente, o en general, de luchar efectivamente contra la proliferación de armas de destrucción masiva". Chirac se mostró complacido por la caída de la dictadura de Saddam Husein, pero, junto con Schroder, piensa que Irak debe gozar de plena soberanía "con la legitimidad que desciende desde Naciones Unidas". Ambos jefes de Estado insistieron en el "papel central que debe desempeñar Naciones Unidas, luego de la fase de 'asentamiento', en la reconstrucción política, humanitaria y administrativa de Irak". Alemania no participará en la reconstrucción de Irak, a menos que Naciones Unidas sea integrada. La tarea principal de este encuentro era volver a retejer las relaciones con Washington, cuando los "más duros", Wolfowitz y Perle, los querían mantener alejados, sobre todo a Francia, por no haber contribuido a los gastos de guerra. Con su participación, Putin pretende integrar más a Rusia en Europa.

Estados Unidos, que pronto comenzó a distribuir los contratos de reconstrucción de Irak a sus propias empresas, pidió - por boca de Wolfowitz- a Berlín, Moscú y París que "eliminen en parte o en todo la deuda externa que Irak tiene con ellos". Estos le respondieron que el alivio de la deuda se hará a través del Club de París y agregaron una postdata. Irak debe unos 4 mil millones de dólares a Alemania, 8 mil millones a Francia y 8.500 millones a Rusia, por préstamos de los años de 1980, "cuando Bagdad estaba en guerra contra Irán, y también se aprovechaba del apoyo de Estados Unidos para adquirir armas" (Le Monde, 11 y 12 de abril de 2003). En la actualidad, la deuda externa de lrak asciende a unos 130 mil millones de dólares, pero se desconocen su origen y el grupo de acreedores. Esto, tal como indicara Chirac, deberá discutirse en el Club de París.

De San Petersburgo no salió ningún documento final. La reunión terminó con una conferencia de prensa, en la cual los gobernantes declararon que a Naciones Unidas le corresponde un papel central en la resolución de la crisis iraquí. Pero, advirtieron, "de conformidad con el derecho internacional, es responsabilidad de las fuerzas angloamericanas, como 'potencias ocupantes', mantener el orden público y asegurar el acceso de la ayuda humanitaria", recordó J. Chirac, y "esperamos que están haciendo lo mejor posible para mantener el orden". Putin indicó que pueden hallarse armas de destrucción masiva, pero sin aclarar quién las pudo haber dejado ahí; si aparecieran tales armas, correspondería a los inspectores de Naciones Unidas estudiar su procedencia. Pero si las armas no se descubren -y hasta ahora no se han descubierto-. Saddam Husein deja de ser una amenaza para Estados Unidos y sus aliados, y cae por tierra "el título colorado", con el cual se justificó la guerra. No queda más salida que el "chivo expiatorio" de Siria.

"No estamos forjando un movimiento 'anti", - declaró Chirac-. "Nuestra visión del mundo excluye el unilateralismo. Estamos a favor del papel de Naciones Unidas y queremos que sea respetada. Y si hay que reformarla, estamos dispuestos a colaborar". Apoyado por Schoder y Putin, Chirac repitió que Naciones Unidas debe tener un papel central en Irak en la reconstrucción, luego de la fase de estabilización. Solo Naciones Unidas será fuente de legitimidad para las futuras autoridades 
iraquíes y solo ella puede garantizar la integridad y la soberanía de la nación. Su experiencia le permite ser eficiente y puede garantizar "un orden regional estable". Chirac dijo, además, que espera con impaciencia el anuncio de la agenda o del plan para la pacificación (del Oriente Próximo), el cual ya llevaba un retraso de tres meses. No es éste el parecer de Powell. "No estamos dispuestos a decir: "muy bien, la guerra ha terminado, vamos a salir para dejar el puesto a Naciones Unidas'. Naciones Unidas tendrá un papel principal, esencialmente en el campo humanitario. Las naciones que han pagado el costo político y el precio de la sangre... para crear las circunstancias que permitan iniciar un nuevo gobierno democrático en Irak, tendrán el papel importante y motor de este proceso", con lo cual dio a entender que corresponde "a sólo los iraquíes escoger sus nuevos gobernantes", si bien Washington ejercerá "cierta influencia" (Le Monde, 13 de abril de 2003).

\section{El principio de un triste final}

Terminamos con más interrogantes que respuestas. "Para el presidente G. W. Bush, la guerra continúa". ¿Cuándo se considerará que la guerra ha terminado? "Cuando los comandantes, allá presentes, me digan que se han logrado los objetivos": la captura o la muerte de Saddam Husein y de sus principales dirigentes y el desmantelamiento de las armas de destrucción masiva. Estas armas pueden estar escondidas en Irak o tal vez se hallan en Siria. "No sabemos si Saddam Husein está vivo o muerto. Lo que sabemos es que no está en el poder". Si las armas químicas o bactereológicas no aparecen, Rumsfeld ya indicó que podrían estar en Siria, que apoyó a Irak.

En consecuencia, Bush advirtió a Damasco: "Siria debe saber que esperamos su total cooperación. Le exigimos con toda firmeza que no dé asilo a miembros del partido Baas o de la familia de Saddam, ni a los generales en fuga. Esperamos que haga cuanto esté en su poder para impedir que personas que pueden ser perseguidas abandonen Irak. Y si ya están en Siria, esperamos que las autoridades sirias las entreguen a las personas competentes". No se indicó quiénes son esas "personas competentes". Wolfowitz, por su lado, indicó que Washington "debe reflexionar su política" respecto a
Siria, "país que apoya al terrorismo" (Le Monde, 13 de abril de 2003). En Corea del Norte proseguirá su lucha para hacer desaparecer las armas nucleares, pero por la vía diplomática.

Estamos ante el principio de un triste final. El dictador Saddam Husein ya no está en el poder; pero el fin no justifica los medios, con todas sus desastrosas consecuencias. Ante todo, el aún desconocido número de vidas sacrificadas, de familias dispersadas, refugiados, exilados, del imponderable dolor y del resentimiento que haya podido sembrar la destrucción de un país rico, sin duda, en recursos naturales ( $\mathrm{y}$ arqueológicos). ¿Quién y cómo lo reconstruirá, cuando la misma reconstrucción es objeto de debate? Se ha sacrificado la historia de un país y esto puede generar resentimientos y respuestas impredecibles, en esta zona caliente del Medio Oriente, porque no habrá paz, mientras haya amenazas.

$\mathrm{Y}$ ien el resto del mundo? Se ha agredido y debilitado el papel conciliador de Naciones Unidas, una de las pocas instituciones mundiales capaz de "construir la confianza" para respetar los derechos humanos durante las guerras y para buscar la equidad económica. ¿Saldrá ahora fortalecida o debilitada Naciones Unidas? Se ha debilitado la conciencia moral de algunos jefes de Estado quienes, conociendo qué es y cómo se hacen las guerras, se aliaron con esta guerra. Respuestas positiva son las manifestaciones y la conciencia de quienes siguen gritando "No a la guerra". Queda en pie el "enfrentamiento de conciencias".

Ha quedado también debilitada "la unidad de la Unión Europea" y los equilibrios diplomáticos tardarán mucho tiempo en restablecerla. También el Atlántico es "un muro" que separa dos visiones distintas del mundo futuro. Se han tejido y se han destejido muchas "alianzas flexibles" entre los maestros del mundo y no es fácil que se sigan mirando como socios, aliados y amigos. Quedan, a modo de enigma, dos preguntas: ¿la reconstrucción de la economía estadounidense se hará gracias a la destrucción de la economía iraquí? y ¿quién y cuándo podrá reconstruir al "Dios, la conciencia y la historia" del actual gobiemo de Estados Unidos? 